\title{
LAPAROSCOPIC MANAGEMENT OF DEEP INFILTRATING COLORECTAL ENDOMETRIOSIS
}

\author{
Nicolae BACALBASA ${ }^{1,2} \bowtie$, Irina BALESCU ${ }^{3}$, Mihaela VILCU ${ }^{1,2}$, Iulian BREZEAN ${ }^{1,2}$ \\ ${ }^{1}$ „Carol Davila“ University of Medicine and Pharmacy, Bucharest, Romania \\ 2 „Ion Cantacuzino“ Clinical Hospital, Bucharest, Romania \\ ${ }^{3}$ Ponderas Academic Hospital, Bucharest, Romania
}

Received 26 Aug 2019, Accepted 16 Oct 2019

https://doi.org/10.31688/ABMU.2019.54.4.18

\begin{abstract}
Deep infiltrating endometriosis is a debilitating disease which usually affects young women and significantly impacts on the quality of life. Due to the fact that it remains a benign condition which usually affects patients at the reproductive age, an aggressive, radical surgical procedure might be considered as a too mutilating one by certain cases. In consequence, attention was focused on treating these patients in a less invasive manner, procedures like rectal shaving or full thickness local excision being proposed. In the meantime, once the minimally invasive techniques evolved, laparoscopic surgery has been widely proposed in the last decade in order to treat this pathology. The current paper is a literature review of the largest studies which investigated and compared the outcomes after minimally invasive approach for deep infiltrating colorectal endometriosis.
\end{abstract}

Keywords: colorectal resection, shaving, full thickness resection, endometriosis.

\section{Résumé}

Approche laparoscopique de l'endométriose colorectale à infiltration profonde

L'endométriose à infiltration profonde est une maladie débilitante qui affecte généralement les jeunes femmes et a un impact important sur la qualité de la vie. Du fait qu'il s'agit toujours d'une affection bénigne affectant généralement les patients en âge de procréer, une intervention chirurgicale radicale et agressive peut être considérée comme une mutilation excessive par certains cas. En conséquence, l'attention a été concentrée sur le traitement de ces patients de manière moins invasive, des procédures comme le rasage rectal ou l'excision locale de l'épaisseur totale étant proposées. Dans l'entre-temps, une fois que les techniques mini-invasives ont évolué, la chirurgie coelioscopique a été largement proposée au cours de la dernière décennie pour traiter cette pathologie. Le présent document est une revue de la littérature des plus grandes études ayant étudié et comparé les résultats après une approche mini-invasive de l'endométriose colorectale à infiltration profonde.

Mots-clés: résection colorectale, rasage, résection, résection de l'épaisseur complète, endométriose. 


\section{INTRODUCTION}

Defined by the presence of nodules invading the peritoneal surface on a depth of at least $5 \mathrm{~mm}$, deep infiltrating endometriosis is a debilitating disease which might affect various pelvic viscera such as the urinary bladder, small bowel, large bowel, rectum or even other extra- pelvic structures such as the diaphragmatic muscle. In such cases most often the real extent of the disease remains hardly to be evaluated during the preoperative workup, the most appropriate information being obtained Intraoperatively, after a close inspection of all the pelvic and abdominal structures. In these conditions a minimally invasive surgical approach remains the option of choice; this therapeutic strategy is also sustained by the fact that endometriosis is in fact a benign disease which usually affects young women, the wide inspection of the whole abdomen and pelvic structure in a laparoscopic manner being beneficial. When it comes to the deep infiltrating rectal nodules of endometriosis, the option of choice depends on the extent of the lesions which is best evaluated during the laparoscopic exploration $^{1,2}$.

\section{Therapeutic strategies in patients with deep infiltrating colorectal endometriosis}

According to the extent of the disease, patients with colorectal endometriosis can be submitted to different surgical procedures such as rectal shaving, full thickness rectal resection or even colorectal resections. Although nowadays the majority of patients are submitted to colorectal resections, it is widely demonstrated that this approach might be associated with the apparition of the postoperative anterior rectal resection syndrome as well as with other debilitating symptoms and a poor quality of life. Conversely, patients submitted to local excision have a higher risk of developing local recurrences; however, it is estimated that up to $60 \%$ of cases might be initially treated in a conservative manner ${ }^{3}$. According to Roman's paper, what happens now in the field of deep infiltrating endometriosis is similar to the evolution of the concept of radical surgery for breast cancer patients: although initially it has been considered that the only option of choice in such cases remained Halstead's procedure, in time it has been demonstrated that similar oncological outcomes could be provided if less invasive resections were performed such as Patey, Madden or even local resection and lymph node dissection ${ }^{3}$.

As for the management of patients with deep infiltrating endometriosis inducing luminal narrowing, although most authors consider that the only option of choice is represented by colorectal resections, other authors consider that deep shaving alone or in association with disc excision might provide better functional and organic benefits ${ }^{3.5}$. However, the option should be chosen after discussing with the patient and her family about the future potential risks of local complication and recurrence of the disease.

\section{Studies demonstrating the role of laparoscopic colorectal resections in deep infiltrating endo- metriosis}

Colorectal resection for deep infiltrating endometriosis has been considered for a long period of time as the election surgical procedure for deep infiltrating endometriosis. The procedure has been investigated from both the short-term and long-term outcomes and proved to offer a good local control of the disease. When it comes to the surgical approach, the place of the open procedures has been taken recently by the minimally invasive ones; in this way a faster recovery has been provided for these patients. One of the largest studies conducted on the theme of the short- term outcomes after the two types of surgical procedures was published in 2016 in the International Journal of Surgery ${ }^{6}$. The study included 101686 women submitted to colorectal resections, 268 of them being performed for colorectal endometriosis between 2005 and 2014. The authors underlined the fact that the number of cases submitted to colorectal resections for endometriosis increased over time, most often these procedures being performed by the general surgeons. The authors reported a median hospital in stay of 4 days, $14.2 \%$ of cases suffered no complication, 10 cases being readmitted within the first 30 days. When it came to the type of approach, there was no statistical difference between the number of open versus laparoscopic approach; however, patients submitted to a laparoscopic approach benefited from a shorter operative time and a shorter hospital in stay. Therefore, at that moment the authors demonstrated the increasing trend for colorectal resections when compared to conservative procedures in order to treat deep infiltrating endometriosis ${ }^{6}$.

Another important issue is the one regarding the necessity of stoma creation in patients presenting infiltrating nodules with intestinal obstruction. Most often these patients are young and they can hardly accept the idea of an ostomy especially due to the fact that they suffer from a benign condition. In order to avoid ostomy creation in young patients with benign pathology certain authors opined for endoscopic stenting followed by interval laparoscopic resection and anastomosis? 


\section{Studies sustaining the role of the laparoscop- ic conservative approach in deep infiltrating endometriosis}

As for the conservative approach in endometriosis, there are two options of choice which consist of rectal shaving (consisting of resection of the endometrial nodule alone, the continuity of the rectal wall being entirely preserved) or of full thickness resection (in which the nodule is resected in block with the rectal wall, the resulting defect being therefore sutured $)^{8-10}$. However, due to the fact that usually each surgical team prefers one type of surgery versus the other, there is scarce data originating from comparative studies regarding the two conservative methods $3,10,11$. The first study which was conducted on this issue and which realized a comparison between the two methods was published in 2016 in the American Journal of Obstetrics and Gynecology ${ }^{12}$. The study included 46 women submitted to conservative rectal shaving and 25 women submitted to colorectal resections in the Department of Obstetrics and Gynecology at Rouen University Hospital (France). The preoperative investigations demonstrated that there was no significant difference in terms of median diameter of the rectal nodules or associated visceral resections; however, patients submitted to colorectal resections presented a significantly higher level of rectal wall invasion, in this group for cases presenting lesions invading the mucosa (while in the other group no patient presented such lesions); another interesting observation was the one that patients submitted to colorectal resections were rather submitted to surgery before November 2007 - the moment when the new protocol regarding the rectal shaving was introduced. When it comes to cases in which rectal and vaginal resections were performed diverting ostomies were also associated in order to decrease the risk of recto-vaginal leaks. When it comes to the postoperative outcomes, the number of cases which presented postoperative rectal bleeding or stoma related complications was significantly higher among patients who underwent colorectal resections when compared to those in whom rectal shaving had been performed. As for the long-term outcomes, patients submitted to conservative surgery - reported a significantly better quality of life including a lower need for laxative use, a lower number of unsuccessful rectal evacuation, a lower degree of postoperative pain and a lower level of painful evacuation effort. As for the evolution of the disease, four cases among those submitted to rectal shaving developed recurrent disease at the site of the previous shaving, two of them being treated by re-shaving and the other two being treated by colorectal resection; however, none of the patients submitted to colorectal resection did experience any recurrent disease ${ }^{12}$.

One of the most recent studies which compared these three techniques (shaving versus discoid resection versus colorectal resections) was conducted by Gutierrez et al and was published in the European Journal of Obstetrics \& Gynecology and Reproductive Biology in 2019'13. The study included 143 patients submitted to surgery for endometriosis with bowel involvement: 76 cases were submitted to segmental resections, 20 patients were submitted to discoid resections while the remaining 47 cases were submitted to rectal shaving. The authors underlined the fact that a significant difference was seen between the two groups when it comes to the history of previous surgery, the length of surgery, the dimensions and the location of the nodules as well as to the rate of intraoperative complications. Therefore, patients submitted to conservative procedures had a lower rate of preoperative history of previous surgeries, benefited from a shorter length of the surgical procedures and were diagnosed with a lower diameter of the nodules; however, the rate of postoperative complications was higher among cases submitted to conservative procedures. In the meantime, the rate of recurrence was higher among patients submitted to conservative approach, underlining the fact that these procedures should be rather reserved for premenopausal women ${ }^{13}$.

\section{Therapeutic strategies in patients present- ing diffuse infiltration of the colorectal area through multiple endometrial nodules}

When it comes to patients presenting multiple endometrial nodules, certain authors proposed performing a radical resection involving all the nodules leading to extended colorectal surgical procedures ${ }^{14-16}$. However, this option should be carefully chosen especially due to the fact that endometriosis remains a benign condition and the age of the affected patients is usually low. Therefore, in such conditions a more conservative approach could be beneficial ${ }^{17-19}$. This might consist of multiple local excisions and sutures; in such cases the most important prognostic factor is represented by the length of the free of sutures segment, which should be of at least $50 \mathrm{~mm}$ (due to the fact that closer than $50 \mathrm{~mm}$ sutures are rather considered as being ischemic) ${ }^{3}$. One case which comes to demonstrate the efficacy of local excision in patients presenting multiple endometrial nodules invading the colorectal area has been included in the ENDORE clinical trial. In this case the patient had been diagnosed with three nodules involving the rectum (with a maximal length of $4 \mathrm{~cm}$ ), the sigmoid colon (with a maximum length of $3 \mathrm{~cm}$ ) and the transverse colon 
(and measuring $2 \mathrm{~cm}$ in length). According to the traditional model, the patient would had been submitted to a total colectomy with the preservation of the last $3-4 \mathrm{~cm}$ of the rectum; however, the authors decided to perform three separate full thickness resections and reported a favorable postoperative outcome at the four- year follow-up ${ }^{20}$.

\section{Conclusions}

In patients presenting deep infiltrating colorectal endometriosis multiple therapeutic strategies have been proposed so far, with promising results. However, the option of choice should be tailored in each case according to patient's history, extent of the disease and wish. According to the latest studies, a significant number of cases might benefit from less extended procedures.

\section{Acknowledgements}

This work was supported by the project entitled „Multidisciplinary Consortium for Supporting the Research Skills in Diagnosing, Treating and Identifying Predictive Factors of Malignant Gynecologic Disorders", project number PN-III-P1-1.2-PCCDI2017-0833.

\section{Compliance with Ethics Requirements:}

„The authors declare no conflict of interest regarding this article"

"The authors declare that all the procedures and experiments of this study respect the ethical standards in the Helsinki Declaration of 1975, as revised in 2008(5), as well as the national law."

\section{References}

1. Koninckx PR, Martin D. Treatment of deeply infiltrating endometriosis. Curr Opin Obstet Gynecol 1994; 6(3): 231-241.

2. Roman H, Vassilieff M, Gourcerol G, et al. Surgical management of deep infiltrating endometriosis of the rectum: pleading for a symptom-guided approach. Hum Reprod 2011; 26(2): 274-281.

3. Darwish B, Roman H. Surgical treatment of deep infiltrating rectal endometriosis: in favor of less aggressive surgery. Am J Obstet Gynecol 2016; 215(2): 195-200.

4. Roman H, Abo C, Huet E, et al. Full-thickness disc excision in deep endometriotic nodules of the rectum: a prospective cohort. Dis Colon Rectum 2015; 58(10): 957-966.
5. Roman H. Deep rectal shaving using plasma energy for endometriosis causing rectal stenosis - a video vignette. Colorectal Dis 2014; 16(10): 834-836.

6. Thiels CA, Shenoy CC, Ubl DS, Habermann EB, Kelley SR, Mathis KL. Rates, trends, and short-term outcomes of colorectal resections for endometriosis: An ACS-NSQIP review. Int J Surg 2016; 31: 5-9.

7. Calcagno P, Viti M, Cornelli A, Galli D, D'Urbano C. Intestinal obstruction caused by endometriosis: Endoscopic stenting and expedited laparoscopic resection avoiding stoma. A case report and review of the literature. Int J Surg Case Rep 2018; 44: 75-77.

8. Donnez J, Squifflet J. Complications, pregnancy and recurrence in a prospective series of 500 patients operated on by the shaving technique for deep rectovaginal endometriotic nodules. Hum Reprod 2010; 25(8): 1949-1958.

9. Fanfani F, Fagotti A, Gagliardi ML, et al. Discoid or segmental rectosigmoid resection for deep infiltrating endometriosis: a case-control study. Fertil Steril 2010; 94(2): 444-449.

10. Kondo W, Ribeiro R, Zomer MT, Hayashi R. Laparoscopic double discoid resection with a circular stapler for bowel endometriosis. J Minim Invasive Gynecol 2015; 22(6): 929-931.

11. Darai E, Dubernard G, Coutant C, Frey C, Rouzier R, Ballester M. Randomized trial of laparoscopically assisted versus open colorectal resection for endometriosis: morbidity, symptoms, quality of life, and fertility. Ann Surg 2010; 251(6): 1018-1023.

12. Roman H, Milles M, Vassilieff M, et al. Long-term functional outcomes following colorectal resection versus shaving for rectal endometriosis. Am J Obstet Gynecol 2016; 215(6): 762.

13. Gutiérrez AH, Spagnolo E, Zapardiel I, et al. Post-operative complications and recurrence rate after treatment of bowel endometriosis: Comparison of three techniques. European Journal of Obstetrics $\mathcal{E}$ Gynecology and Reproductive Biology 2019; X 4:100083.

14. Bratu OG, Cherciu AI, Bumbu A, et al. Retroperitoneal tumors - treatment and prognosis of tumor recurrence. Rev Chim (Bucharest) 2019;70(1):191-194.

15. Bodean $\mathrm{O}$, Bratu $\mathrm{O}$, Munteanu $\mathrm{O}$, et al. Iatrogenic injury of the low urinary tract in women undergoing pelvic surgical interventions. Arch Balk Med Union 2018;53(2):281-284.

16. Spinu DA, Marcu RD, Socea B, et al. Ureteral JJ stents: which one is better? Rev Chim (Bucharest) 2018;69(8):2061-2063.

17. Bodean O, Bratu OG, Bohiltea R, et al. The efficacy of synthetic oral progestin pills in patients with severe endometriosis. Rev Chim (Bucharest) 2018;69(6):1411-1415.

18. Diaconu CC, Arsene D, Balaceanu A, Bartos D. A rare tumor revealed by abdominal trauma: case presentation. Romanian Journal of Morphology and Embryology 2014;55(3):973-976.

19. Tiglis M, Neagu TP, Elfara M, et al. Nefopam and its role in modulating acute and chronic pain. Rev Chim (Bucharest) 2018;69(10):2877-2880.

20. Roman H, Tuech JJ, Slim K, Canis M. Functional outcomes of surgical management of deep endometriosis infiltrating the rectum (ENDORE). NCT01291576. Available at http://clinicaltrials.gov/ct2/show/NCT01291576?term¹/4 NCT01291576\& rank1/41; 2011. (Accessed August 9, 2019) 